\title{
Effects of Diet, Nutrition, and Exercise in Children With Autism and Autism Spectrum Disorder: A Literature Review
}

Shriya Doreswamy ${ }^{1,2}$, Anam Bashir $^{1}$, Jesus E. Guarecuco ${ }^{3}$, Simmy Lahori ${ }^{4,5}$, Ayesha Baig ${ }^{5}$, Lakshmi Rekha Narra ${ }^{6}$, Pinal Patel ${ }^{1}$, Stacey E. Heindl ${ }^{1,7}$

1. Internal Medicine, California Institute of Behavioral Neurosciences and Psychology, Fairfield, USA 2. Otorhinolaryngology, Vydehi Institute of Medical Sciences and Research Centre, Bangalore, IND 3. Neuroscience and Psychology, California Institute of Behavioral Neurosciences and Psychology, Fairfield, USA 4. Medicine, Pramukhswami Medical College, Karamsad, Anand, IND 5. Medicine, California Institute of Behavioral Neurosciences and Psychology, Fairfield, USA 6. Anesthesiology, California Institute of Behavioral Neurosciences and Psychology, Fairfield, USA 7. Internal Medicine, Avalon University School of Medicine, Willemstad, CUW

Corresponding author: Shriya Doreswamy, dr.shriyanara@gmail.com

\begin{abstract}
Diet and nutrition play an important and essential role in everyone's life. It helps build a healthy body and a strong mind. We know that food rich in nutrients can remove toxins from the body, make an excellent immune system, curb hunger, and prevent obesity. Obesity is one of the most concerning, alarming, and fastest-growing pandemics. It affects not only adults but also adolescents and children. The disease's earlyonset calls for prompt attention to control the physical, psychological, financial, and social burden it creates. Children with autism and autism spectrum disorders (ASDs) are commonly affected by eating disorders. Their preference for energy-dense food with low nutrition can alter their metabolism, leading to the accumulation of oxidative radicals, causing them to deteriorate mentally and physically. Although dieting and losing weight are now commonly seen in the general population, it has become hard to bring awareness to children with special needs about diet, nutrition, and obesity. Despite efforts, parents of such children usually cannot help control the eating because tantrums and behavioral problems are common. It is now imperative for doctors and parents to work alongside nutritionists and dieticians to help these children eat healthy to be fit and improve the quality of life.
\end{abstract}

Received 10/28/2020 Review began 11/21/2020 Review ended 12/07/2020 Published 12/22/2020

\section{(c) Copyright 2020}

Doreswamy et al. This is an open access article distributed under the terms of the Creative Commons Attribution License CC-BY 4.0., which permits unrestricted use, distribution, and reproduction in any medium, provided the original author and source are credited.
Categories: Family/General Practice, Pediatrics, Public Health

Keywords: applied behavioral analysis (aba), autism, autism spectrum disorder, diet, nutrition and exercise, pediatric assessment, metabolism, supplements, gluten-free diet, complementary and alternative medicine (cam)

\section{Introduction And Background}

Uncontrolled and unhealthy eating habits commonly lead to physical changes such as being overweight and obesity in the population. These body changes alter our well-being, leading to multiple health issues by causing high cholesterol, high triglycerides, high blood sugar, and electrolyte imbalance. Comorbidities like diabetes mellitus (DM), coronary artery disease (CAD), stroke, and many more disorders become common $[1]$.

Persons with uncontrolled eating habits may have undiagnosed eating disorders (ED). Studies indicate that ED may be one of the significant contributors to comorbidities [2]. Children with neurodevelopmental disorders such as autism and autism spectrum disorders (ASDs) are the commonest population to manifest with ED when compared to the general population [2]. Recent studies indicate that up to three percent of children or at least one in 68 children in the USA may have autism and ASD [3,4]. Children with autism and ASD have reduced social interactions, no eye contact, repetitive stereotypic sensory and motor behaviors, and reduced to no communication with others [4]. Reports also indicate that individuals with autism and ASD are less likely to participate in any physical activity, leading to overweight and obesity [5]. These children are noted to be picky eaters and prefer junk food: calorie-dense, carbohydrate-dense with high sodium, and less nutrition [1].

It is our duty as doctors and parents to nourish the culture of eating healthy as children with special needs may not completely understand the concept and the benefits of healthy and nutritious food [4]. Food rich in macronutrients such as proteins, fats, and micronutrients such as vitamins and minerals, acts as antioxidants and improves these children's better functioning [3]. Interestingly, studies from Catassi et al. suggesting a gluten-free diet and Żarnowska et al. proposing a carbohydrate-free ketone diet (KD) have shown tremendous improvement in the behavior and cognitive skills of these children $[6,7]$.

The decreased physical activities and increased erratic food habits can also lead to long-term health imbalance and societal costs of overweight and obesity in this population [8]. The health burden does not limit to just medication bills but includes their nutritionist, dietician, and pediatrician fees. In their study, 
Criado et al. mention that the societal costs include special education, occupational therapy, speech therapy, applied behavioral analysis (ABA) therapy in these children, which are not covered by the insurance [1]. The study also mentions three other studies that talk about pharmacotherapy, where medications like antipsychotics used in treating ASD and autism can further be one of the causes of unintentional weight gain due to side effects [1].

Although pediatricians measure height, weight, and body mass index (BMI) on every well-child visit, very little progress is made to curb obesity and overweight and promote healthy food habits. Many studies also indicate that parents of children with autism and ASD have no formal education, belong to high socioeconomic status, have reduced sleep and affective problems that significantly contribute to their condition $[1,5]$. Reports indicate that at least 30 percent of the ASD and autistic children fall under the obese category [3,4]. We know unhealthy eating habits in children get carried forward to adolescence and adulthood, leading to obesity that reduces life quality and causes comorbidities. A genetic link between autism and ASD with food habits, drug efficacy, and potency needs research in these children. It is necessary to establish a streamlining of nutrition and physical activity for children with autism and ASD. In this paper, we review articles and arrive at collective data to help primary care physicians, pediatricians, parents, and everyone involved with the treatment of autism and ASD children to improve their lifestyle.

\section{Review}

\section{Methods}

On PubMed, we used the medical subject heading (MeSH) words "Autism," "Autism Spectrum Disorders," and "Obesity" to search for articles between the years 2000 and 2020 initially. Since the data was insufficient, we extended the number of years by another 20 years to 1980 . This search yielded 69 papers that were all in English. We applied the population's inclusion criteria as under 18 years of age, all human studies, and available for free full-text articles. It resulted in 30 papers, including literature reviews, case-control studies, meta-analysis studies, and surveys. We used the same words on Google Scholar, which yielded us 200 results, and with all the inclusion criteria mentioned above, we got 11 results that were of importance to us. We also referred to the Centers for Disease Control (CDC) website, which yielded us one paper. For the nutritional studies on autistic and ASD children, we used the words "Diet" and "Nutrition" in "Autism and ASD" on $\mathrm{MeSH}$, which yielded us 345 articles, of which only 156 had free full-text articles in the same time frame of 40 years. We chose papers that were most relevant to our topic of interest, and we were left with 10 studies. In our final report, we used 27 articles to remove all the duplicate papers and essays.

\section{Results}

Using the inclusion criteria of obesity, nutrition, and diet in human studies under 18 years of age, applying filtration criteria of papers in the past 40 years in the English language only, we were left with 27 studies that were most relevant to our article and hence included them. Through these papers, we were able to determine the relationship between diet and nutrition in children with autism and ASD and improve their functionality.

\section{Discussion}

\section{Pediatric Assessment}

Every well-child visit mandates an evaluation of obesity. These evaluations are done mainly by pediatricians or primary care providers. The CDC defines BMI as an individual that falls above the 95th percentile of weight on the scale [4]. It is the same in all children, including autistic and ASD children. Many pediatricians do not receive training to manage overweight and obesity, let alone managing these conditions in autistic or ASD children [3]. Hence, they usually refer these children to a developmental pediatrician or a dietician for exquisite counseling and management [4]. They also associate this unmanageability with the intelligence quotient (IQ) of the children [9]. The CDC puts forth that children with ASD have varying IQs, as can be seen in Table $1[10]$

\begin{tabular}{|l|l|}
\hline IQ & Level of Intelligence \\
\hline$<70$ & Intellectual disability \\
\hline $71-85$ & Borderline range \\
\hline 85 & Average or higher range \\
\hline
\end{tabular}

TABLE 1: Classification of intelligence quotient (IQ) 
In the last few years, developmental pediatricians diagnose autism as early as 18 months [4]. Early diagnosis and early interventions through therapies such as speech, occupational, and ABA therapy help them improve intellectually and teach them life skills that help them interact with peers and improve their sensory and motor skills, including table manners [11]. Although these interventions promise good behavioral outcomes, it is mandatory to organize their diet to control obesity.

Streamlining Nutrition and Diet

Curtin et al. discuss in their study that it is essential for children to develop clean eating habits and incorporate family practices like sitting down at the table for a meal, not watching gadgets or television, having a family conversation, and learn to eat on their own [11]. Children with autism and ASD find it most challenging to adapt to new food and new rules around food [12]. Hill et al. mentioned in their studies that autistic and ASD children prefer energy-dense, nutrient-deficient foods and reject fruits, vegetables, and whole grains [5]. The autistic and ASD children are "picky eaters" with preference to only certain food types, tastes, and textures; hence selective eating becomes a huge problem for parents and everyone dealing with them [12]. Parents must teach good eating habits in these children right from when they are weaned from mother's milk to help curb these problems.

Along with the above, a specialized diet in place and restricted food preferences, introduction to a new food or physical activity, can frequently cause disruptive behavior that ultimately leads parents to budge to their demands [12]. Hence, new foods should be introduced to these children in phases to ensure familiarity with the food's taste and texture [13]. While all these studies only mention the intervention, it does not describe the methods, timing, or the phases of the introduction of food that we can do.

\section{Alteration in Metabolism}

A study by Żarnowska et al. in 2018 conducted a therapeutic use of carbohydrate-restricted diet/KD in an autistic child that concluded significant clinical outcomes like better attention span, communication skills, reduced fear, anxiety, and emotional disturbances. They also attributed the personal and behavioral changes to reduced gene expression in the mitochondria and reduced activity in mitochondria's electron chain [7]. Studies by Napoli et al. in 2014 and Cheng et al. in 2017 showed that individuals on a carbohydrate-less diet became ketone dependent, decreasing mitochondrial function and reducing their energy requirements to show significant behavior improvement [14,15]. Although this research has generated a powerful insight into the mechanism, it is necessary to have further studies to prove the research.

Vitamins and Mineral Supplements

Vitamins and mineral supplements are essential in children with autism and ASD as they are considered highly beneficial. Many of these vitamins and minerals act as co-enzymes and neurotransmitters for numerous biochemical enzymatic reactions in our bodies. Adams et al. did a randomized control study for three months that deciphered that low levels or absence of vitamins and minerals can result in impaired metabolic functioning [16]. The study concluded that while the supplements improved biotin, oxidative stress, glutathione, methylation, adenosine triphosphate (ATP), the reduced form of nicotinamide adenine dinucleotide phosphate (NADPH), and sulfate, they also reduced the hyperactivity, tantrum, and overall reception in the language with fewer side effects [16]. Buie et al., Horvath et al., and Ashwood et al. conducted studies that proved that a Parent Global Impression-Revised (PGI-R) score improved significantly [17-19]. A PGI-R score is an indicator of psychosocial impairment in children with special needs, including various factors such as pain and hunger that can be measured [17]. It has high sensitivity, specificity, is highly consistent, reliable, and valid as it determines the effectiveness of all the therapies given to autistic children [20]. These studies' limitations were that they were done on small sample size and needed in-depth research.

Gluten-Free Diet

Research on diet and nutrition in autistic and ASD kids has substantially increased in the past 20 years, specifically to study hyperactivity and attention. Catassi et al. and Cruchet et al. conducted two different studies on nonceliac gluten sensitivity-based, gluten-free diet trials in 2016 and 2013, respectively, on autistic and ASD kids $[6,21]$. The gluten-free diet type of test was first done in the 1980s and recently rediscovered, which hypothesized a possible increase in peptide formation due to incomplete and improper breakdown of food containing gluten and casein [6,21]. A "leaky gut" phenomenon seen in autism and ASD could cause these peptides to cross the blood-brain barrier affecting the endogenous opiate neurotransmission mechanisms, and the removal of these so-called toxins helps the children control their actions and emotions [6,21]. Another study by Robertson et al. compared original research done by Lau et al. regarding intestinal permeation and did not find any intestinal permeability changes, as mentioned by the latter $[22,23]$. Despite all these studies and the popularity of trying different diet plans for these kids, there is more to prove these effects.

Complementary and Alternative Medicine 


\section{Cureus}

Zuckerman et al. mention in their studies that many parents have also explored the options of treating children with chiropractors and dietary supplements, including digestive enzymes, microminerals, no sugar diet, probiotics, yielding inconclusive results [24]. Research by Hofer et al. uses food supplements such as omega-3 fatty acids, folinic acid, L-carnosine, tetrahydrobiopterin, N-acetylcysteine, oxytocin, dimethylglycine to see possible changes in these children [25]. Although these do not give great results, the research is not entirely false either, the reason being, they have all been studied in a tiny population for a brief period. We need more research on this aspect.

Medications

Melatonin is one of the most familiar drugs used in autistic and ASD kids to treat sleep disorders and disturbances and is one of the well-tolerated drugs giving good results. The only drawback is that it is being studied in a tiny population among these kids, as many parents do not want to provide these medications with a fear of severe side effects [25]. Many drugs like antipsychotics, stimulants, and antiepileptics used in treating autism and ASD children play a significant role in gaining weight [5]. In their study, Egan et al. mention no relationship between medications and weight gain, unlike the many other studies in the past $[3]$.

Microbiota

In recent times, the microbiota has become an essential topic of interest. They are necessary for our intestine, unblemished skin, or sound mental and physical health. In 2017, a study by Kang et al. linked gut microbiome to abnormal metabolites and behavior, showing that the transplant of microbiota causes a significant improvement in constipation symptoms, diarrhea, indigestion, abdominal pain, and behavior [26]. For this reason, many parents fed the kids fresh homemade yogurt at least two times a day. Many studies conducted in the past have also concluded that using probiotics is safe and a promising treatment for children with autism and ASD.

Table 2 summarizes the studies mentioned in our discussion. A summary of dietary regulation of metabolism in autistic and ASD children to improve their lifestyle is in Figure 1.

\begin{tabular}{|c|c|c|c|}
\hline Author & Year & Sample Size (N) & Conclusion \\
\hline $\begin{array}{l}\text { Żarnowska } \\
\text { et al. [7] }\end{array}$ & 2018 & 35 and a single case study & $\begin{array}{l}\text { Concluded that the ketone diet shows tremendous improvement in } \\
\text { behavior, eating habits, and tantrums }\end{array}$ \\
\hline $\begin{array}{l}\text { Nadon et } \\
\text { al. [13] }\end{array}$ & $\begin{array}{l}2010 \\
\text { and } \\
2011\end{array}$ & $\begin{array}{l}95 \text { cases, compared autistic } \\
\text { children with non-autistic siblings } \\
\text { from the same family. }\end{array}$ & $\begin{array}{l}\text { Identified sensory problems concerning food and eating habits. Concluded } \\
\text { that sensory habits are completely different and can be haywire in these } \\
\text { children. }\end{array}$ \\
\hline $\begin{array}{l}\text { Napoli et } \\
\text { al. [14] }\end{array}$ & 2014 & N/A & $\begin{array}{l}\text { A ketogenic diet reduces mitochondrial gene expression helping improve } \\
\text { symptoms. }\end{array}$ \\
\hline $\begin{array}{l}\text { Cheng et } \\
\text { al. [15] }\end{array}$ & 2017 & N/A & $\begin{array}{l}\text { A ketogenic diet reduces mitochondrial gene expression, and hence there } \\
\text { is a significant improvement in behavior, hunger, and other major autistic } \\
\text { symptoms. }\end{array}$ \\
\hline $\begin{array}{l}\text { Adams et } \\
\text { al. [16] }\end{array}$ & 2011 & 141 & $\begin{array}{l}\text { Vitamins and minerals have good effects on ASD and autism, improved } \\
\text { PGI-R subscales, tantrums, receptive language. }\end{array}$ \\
\hline $\begin{array}{l}\text { Cruchet et } \\
\text { al. [21] }\end{array}$ & 2016 & N/A & $\begin{array}{l}\text { Nonceliac gluten sensitivity diet and vegetarian diet improve the behavioral } \\
\text { outcome. }\end{array}$ \\
\hline $\begin{array}{l}\text { Zuckerman } \\
\text { et al. [24] }\end{array}$ & 2015 & 376 & $\begin{array}{l}\text { Complementary and alternative medicines worked better for most children. } \\
\text { Reduced medication and melatonin worked great with the least side } \\
\text { effects and improvement in sleep. }\end{array}$ \\
\hline $\begin{array}{l}\text { Jones et } \\
\text { al. [27] }\end{array}$ & 2017 & 35 & $\begin{array}{l}\text { Increased socialization, motor skills, and physical activity regulates hunger } \\
\text { and changes social-emotional and developmental functioning. }\end{array}$ \\
\hline
\end{tabular}




\section{Cureus}

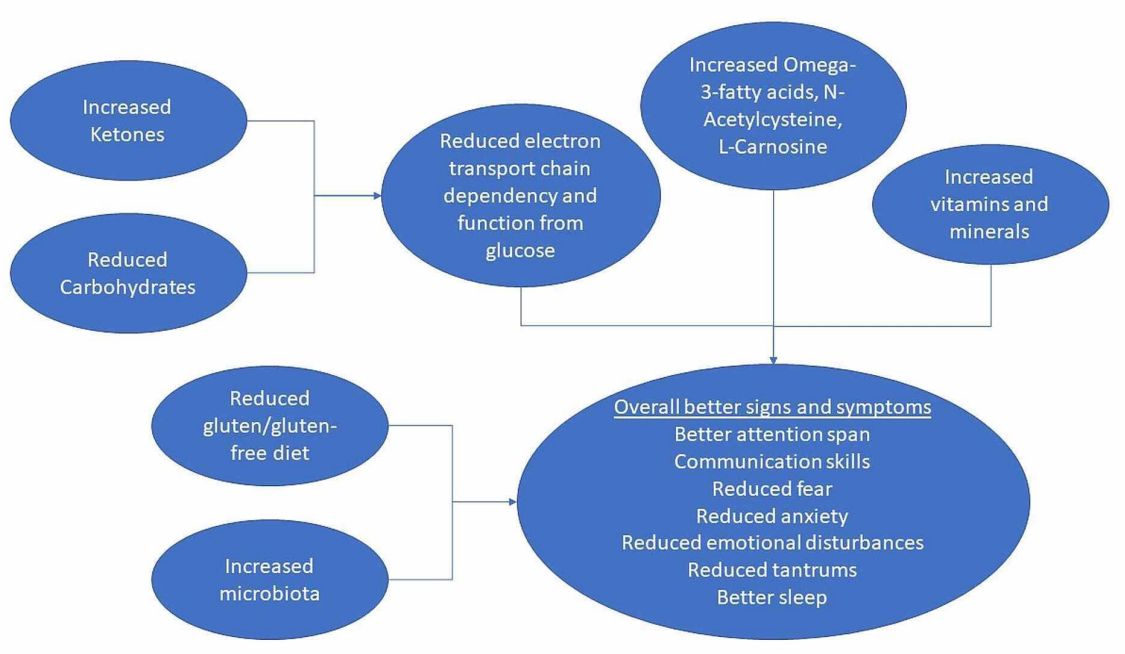

FIGURE 1: Dietary regulation of metabolism in autistic and ASD children ASD: Autism spectrum disorder

Therapy

As we mentioned earlier, it is imperative to recognize the signs and symptoms first and intervene early for best results. Early intervention also ensures adequate exposure to different people, various environments, and situations, identifying possible stressors, and working on them. ASD and autistic children need to mingle with typically developing children as their company helps them grow emotionally and socially, improve physical health, broaden their outlook towards life, increase interests in different aspects, and strengthen motor skills [27]. Exercising also boosts metabolism and can regulate hunger and satiety centers for food [9]. Therapies such as occupational, speech, and ABA help deal with all the sensitivities and activities necessary to get back to the "normal" or "typical" group while creating a conducive environment for these children to improve their quality of life [12]. The significant drawbacks are that insurance does not cover many of these therapies and can cause a tremendous burden on the caregivers' pockets.

\section{Limitations}

Our study has aimed to put forth the connection that children with autism and ASD have with food habits. Although studies show significant changes in behavior, emotion, and cognitive skills in autistic and ASD children due to small changes in food habits, there is no concrete evidence to prove the same. Most of the studies are done only on a small population of autistic children. The data we collected focuses on a population mostly in the Western world, including developed countries, and does not include third-world countries. A few other limitations to this topic are that few articles are available, limited knowledge among the primary caregivers and pediatricians, and, most of all, little reporting and treatment of such children that significantly affect the results.

\section{Conclusions}

Challenging situations promote thought-provoking questions, which further lead to in-depth research and analysis. One such topic is autism. Developmental pediatricians and doctors treating adult autistic and ASD cases commonly say that every autistic person is unique. Everyone has different signs and symptoms or challenges. To better understand the patients, we first need to train the providers. We should survey the pediatricians and parents to know more about their challenges, particularly food and food habits. Changes and interventions should be brought about in children as early as possible to give them a better quality of life. Just like food, physical activity plays an equally important role in managing these children. Physical activity helps in weight management and helps release their stresses along with providing social interactions. It also releases the 'feel-good hormones' or the endorphins that help in faster healing. A trial and error of diets is a must to see what suits them best. The medications need to be titrated and monitored as one medicine can act differently in different autistic children and autistic adults. For all these to function correctly, the providers, therapists, dieticians, parents, and everyone involved need to work hand in hand. To draw conclusive results, the federal government must give more grants, plenty of research, and, most of all, all expenditure needs to be covered by the insurance. Do we conclude by wondering if obesity is linked to genetic causes, and will we manage it in these children? Only further studies and research will tell.

\section{Additional Information}




\section{Disclosures}

Conflicts of interest: In compliance with the ICMJE uniform disclosure form, all authors declare the following: Payment/services info: All authors have declared that no financial support was received from any organization for the submitted work. Financial relationships: All authors have declared that they have no financial relationships at present or within the previous three years with any organizations that might have an interest in the submitted work. Other relationships: All authors have declared that there are no other relationships or activities that could appear to have influenced the submitted work.

\section{References}

1. Criado KK, Sharp WG, McCracken CE, et al.: Overweight and obese status in children with autism spectrum disorder and disruptive behavior. Autism. 2018, 22:450-459. 10.1177/1362361316683888

2. Wentz E, Björk A, Dahlgren J: Is there an overlap between eating disorders and neurodevelopmental disorders in children with obesity?. Nutrients. 2019, 11:2496. 10.3390/nu11102496

3. Egan AM, Dreyer ML, Odar CC, Beckwith M, Garrison CB: Obesity in young children with autism spectrum disorders: prevalence and associated factors. Child Obes. 2013, 9:125-131. 10.1089/chi.2012.0028

4. Christensen DL, Maenner MJ, Bilder D, et al.: Prevalence and characteristics of autism spectrum disorder among children aged 4 years - Early Autism and Developmental Disabilities Monitoring Network, seven sites, United States, 2010, 2012, and 2014. MMWR CDC Surveill Summ. 2019, 68:1-19. 10.15585/mmwr.ss6802a1

5. Hill AP, Zuckerman KE, Fombonne E: Obesity and autism. Pediatrics. 2015, 136:1051-1061. 10.1542/peds.2015-1437

6. Catassi C, Bai JC, Bonaz B, et al.: Non-celiac gluten sensitivity: the new frontier of gluten related disorders . Nutrients. 2013, 5:3839-3853. 10.3390/nu5103839

7. Żarnowska I, Chrapko B, Gwizda G, Nocuń A, Mitosek-Szewczyk K, Gasior M: Therapeutic use of carbohydrate-restricted diets in an autistic child; a case report of clinical and 18FDG PET findings. Metab Brain Dis. 2018, 33:1187-1192. 10.1007/s11011-018-0219-1

8. Khalife N, Kantomaa M, Glover V, et al.: Childhood attention-deficit/hyperactivity disorder symptoms are risk factors for obesity and physical inactivity in adolescence. J Am Acad Child Adolesc Psychiatry. 2014, 53:425-436. 10.1016/j.jaac.2014.01.009

9. Walls M, Broder-Fingert S, Feinberg E, Drainoni ML, Bair-Merritt M: Prevention and management of obesity in children with autism spectrum disorder among primary care pediatricians. J Autism Dev Disord. 2018, 48:2408-2417. 10.1007/s10803-018-3494-0

10. Baio J, Wiggins L, Christensen DL, et al.: Prevalence of autism spectrum disorder among children aged 8 years - Autism and Developmental Disabilities Monitoring Network, 11 sites, United States, 2014. MMWR CDC Surveill Summ. 2018, 67:1-23. 10.15585/mmwr.ss6706a1

11. Curtin C, Must A, Phillips S, Bandini L: The healthy weight research network: a research agenda to promote healthy weight among youth with autism spectrum disorder and other developmental disabilities. Pediatr Obes. 2017, 12:e6-e9. 10.1111/ijpo.12109

12. Dawson G, Rogers S, Munson J, et al.: Randomized, controlled trial of an intervention for toddlers with autism: the Early Start Denver Model. Pediatrics. 2010, 125:e17-e23. 10.1542/peds.2009-0958

13. Nadon G, Feldman DE, Dunn W, Gisel E: Association of sensory processing and eating problems in children with autism spectrum disorders. Autism Res Treat. 2011, 2011:541926. 10.1155/2011/541926

14. Napoli E, Dueñas N, Giulivi C: Potential therapeutic use of the ketogenic diet in autism spectrum disorders . Front Pediatr. 2014, 2:69. 10.3389/fped.2014.00069

15. Cheng N, Rho JM, Masino SA: Metabolic dysfunction underlying autism spectrum disorder and potential treatment approaches. Front Mol Neurosci. 2017, 10:34. 10.3389/fnmol.2017.00034

16. Adams JB, Audhya T, McDonough-Means S, et al.: Effect of a vitamin/mineral supplement on children and adults with autism. BMC Pediatr. 2011, 11:111. 10.1186/1471-2431-11-111

17. Buie T, Campbell DB, Fuchs GJ, et al.: Evaluation, diagnosis, and treatment of gastrointestinal disorders in individuals with ASDs: a consensus report. Pediatrics. 2010, 125:S1-S18. 10.1542/peds.2009-1878C

18. Horvath K, Perman JA: Autistic disorder and gastrointestinal disease. Curr Opin Pediatr. 2002, 14:583-587. 10.1097/00008480-200210000-00004

19. Ashwood P, Anthony A, Pellicer AA, Torrente F, Walker-Smith JA, Wakefield AJ: Intestinal lymphocyte populations in children with regressive autism: evidence for extensive mucosal immunopathology. J Clin Immunol. 2003, 23:504-517. 10.1023/B:JOCI.0000010427.05143.bb

20. Wehmeier PM, Schacht A, Dittmann RW, Döpfner M: Global impression of perceived difficulties in children and adolescents with attention-deficit/hyperactivity disorder: reliability and validity of a new instrument assessing perceived difficulties from a patient, parent and physician perspective over the day. Child Adolesc Psychiatry Ment Health. 2008, 2:10. 10.1186/1753-2000-2-10

21. Cruchet S, Lucero Y, Cornejo V: Truths, myths, and needs of special diets: attention-deficit/hyperactivity disorder, autism, non-celiac gluten sensitivity, and vegetarianism. Ann Nutr Metab. 2016, 68:43-50. 10.1159/000445393

22. Robertson MA, Sigalet DL, Holst JJ, Meddings JB, Wood J, Sharkey KA: Intestinal permeability and glucagonlike peptide-2 in children with autism: a controlled pilot study. J Autism Dev Disord. 2008, 38:1066-1071. 10.1007/s10803-007-0482-1

23. Lau NM, Green PHR, Taylor AK, et al.: Markers of celiac disease and gluten sensitivity in children with autism. PLoS One. 2013, 8:e66155. 10.1371/journal.pone.0066155

24. Zuckerman KE, Hill AP, Guion K, Voltolina L, Fombonne E: Overweight and obesity: prevalence and correlates in a large clinical sample of children with autism spectrum disorder. J Autism Dev Disord. 2014, 44:1708-1719. 10.1007/s10803-014-2050-9

25. Höfer J, Hoffmann F, Bachmann C: Use of complementary and alternative medicine in children and adolescents with autism spectrum disorder: a systematic review. Autism. 2016, 21:387-402. 


\section{Cureus}

$10.1177 / 1362361316646559$

26. Kang DW, Adams JB, Gregory AC, et al.: Microbiota Transfer Therapy alters gut ecosystem and improves gastrointestinal and autism symptoms: an open-label study. Microbiome. 2017, 5:10. 10.1186/s40168-0160225-7

27. Jones RA, Downing K, Rinehart NJ, et al.: Physical activity, sedentary behavior and their correlates in children with autism spectrum disorder: a systematic review. PloS One. 2017, 12:e0172482. 10.1371/journal.pone.0172482 